\title{
Evolution of immunoassay with reference to HIV: brief review
}

\author{
Sharma R K ${ }^{1}$, Sharma S K ${ }^{2}$, Brij Bhushan ${ }^{3}$, Sharma D#, Arun Kumar \#,Chhabra $\mathbf{R}^{6}$,Soni G R $\mathbf{R}^{7}$, Singh $\mathrm{S}^{8}$ \\ ${ }^{1}$ Dr.Rajesh K. Sharma, ${ }^{2}$ Sanjeev K. Sharma, ${ }^{3}$ Brij Bhushan, ${ }^{4}$ Deepa Sharma\#, ${ }^{5}$ Arun Kumar\#, ${ }^{6}$ Dr. Reba Chhabra, ${ }^{7}$ Dr.G. \\ R. Soni $\&^{8}$ Dr.Surinder Singh. National Institute of Biologicals, Noida201309 INDIA. \# Bench Biologist, National \\ Institute of Biologicals, Noida, 201309, INDIA.
}

Address for correspondence: Dr. Rajesh K. Sharma, Email: rksharma@nib.gov.in

\begin{abstract}
Evolution of rapid test kit and development from first to fourth generation HIV ELISA and CLIA have resulted in high automation, high through put as well as increased sensitivity and specificity. The window period of HIV has decreased whereas blood safety has increased significantly. Despite of all the progress made so far screening test detecting antigen and / or antibodies, although highly effective in identifying infected persons, will not always detect all individuals who are infected and do not correctly classify persons who are not infected. Different generation of ELISA kits have pros \& cons and can be used in different algorithm of HIV testing.
\end{abstract}

Key Words: Immunoassay, Enzyme Linked Immunosorbent Assay, Chemiluminescence Immunoassay, Human Immunodeficiency Virus

\section{Introduction}

Immunoassay, in general, is a technique used to detect and / or quantify specific proteins present in the sample of interest through binding of antigen and antibody. The word immunoassay is originated from immunology, immunology is a whole subject at present but it borns from the microbiology, and microbiology is an innate from botany, a basic field of life sciences. The Nobel Prize winner Rosalyn Yalow and Solomon Berson described the immunoassay in 1960[1] and becomes the founder of immunoassay. They developed RadioImmunoassay (RIA) for measurement of blood glucose levels in diabetic patient. Since then through antigen antibody binding, detection and measuring of simple to complex biomolecules initiative even those which were either not detected or not suitable by physical and / or chemical methods. The performance of immunoassay was enhanced after development of Enzyme Linked Immunosorbent Assay (ELISA) by Engvali \& Perlmann in 1971[2]. After this revolution the use of RIA gradually decreased because of the use of health hazards radioactive substances, which has tremendous disadvantages from the beginning to till disposal. The ELISA very rapidly attracted the researchers because of

Manuscript received: $15^{\text {th }}$ Oct 2015

Reviewed: $28^{\text {th }}$ Oct 2015

Author Corrected: $13^{\text {th }}$ Nov 2015

Accepted for Publication: $22^{\text {nd }}$ Nov 2015 use of non-radioactive materials, higher sensitivity and specificity and less reaction time as compared to RIA.

Enzyme Linked Immunosorbent Assay (ELISA): It is also known as an Enzyme Immunoassay (EIA), is a biochemical technique used mainly in immunology to detect the presence of an antibody or an antigen in a sample [3]. Some ELISAs are also designed to detect substance like peptides, proteins and hormones. This technique was established and demonstrated by publication on quantitative assays of immunoglobulin $\mathrm{G}$ by Engvell and Perlmann[4] with alkaline phosphatase as the reporter label[5]. Van Weemen and Schuurs work on immunoassay using antigen-enzyme conjugates, they used horse radish peroxidase enzyme for conjugation of the antigen human gonadotropin [6]. ELISA is commonly used as a diagnostic tool to detect and / or quantify disease in early stage and help to clinician for treatment and save lives. It is also used as quality control measures in various industries and in a biomedical research as an analytical tool s[7]. Of various types of ELISA innovated the Direct ELISA was developed initially, in which immunosorbent (antigen) is bound to a solid support, and react with antibodies, if present in the sample, which is tagged to an enzyme, after adding substrate produce colour. The intensity of colour is directly correlating the 
concentration of antibody present in the sample. This is measured through spectrophotometry like ELISA reader and calculates the cut off as well as S/Co. This is a simple ELISA but it has some disadvantages like having moderate sensitivity and low specificity. The other kind of ELISA is a modification of this basic ELISA techniques. An Indirect ELISA is almost same as Direct ELISA, important difference is one additional antibody is added during assay. It has better sensitivity than Direct ELISA and resulted in improved specificity. For sample antigen detection highly efficient ELISA is a Sandwich ELISA, in this primary known antibody immobilized of the solid surface and capture the antigen, if present in the sample, the enzyme labelled secondary antibody bind with primary antibody complex and unbound primary antibody and antigen wash out during washing steps. The advantage of this assay is good sensitivity and specificity. The competitive ELISA is a different kind of ELISA in which the patient antibodies compete with controlled labelled antibody for binding to pre-coated antigen. This assay has more specificity than Direct \& Indirect ELISA because of using two antibodies. To diagnose viral diseases like hepatitis B surface antigen (HBsAg) through EIA was developed in 1976[8] featuring a 96 wellplate format[5]. The first HIV antibody detection test was commercially available in 1985[9]. Food and Drug Administration (FDA), USA gave first licence for detection of antibody to Hepatitis C Virus (Anti-HCV) in $1990[10,11]$.

Rapid Immunoassay: Although ELISA's are used all over the globe but actual revolution came after development of Rapid Immunoassay. Like an ELISA rapid assay also work on same principle of antigenantibody reactions. This assay has quick turnaround time, can be applied outside the sophisticated laboratory, it is a very convenient tool to transport and used at rural, urban, remote, and even tropics areas as such assay does not need electricity. Some rapid kits used dried blood spots, oral fluid, urine etc. as a sample. Rapid assay in low cost, gives fast result and does not Comparison of various generation of ELISA's require highly skilled specialist even some test can be performed by clinician at their clinic like malaria rapid diagnostic test, pregnancy test and glucose strip test etc. Either of two techniques are used in Rapid immunoassay i.e. lateral flow rapid tests or flow through rapid tests. The technique of lateral flow rapid test derived from latex agglutination assay and was developed in 1956 by Plotz and Singer [12]. In this assay sample placed in sample window then added the buffer for movement or flow the sample across the strip and shows result. In flow through substances like antigen antibody are bound on the porous membrane. Rapid test for HIV was developed in 1990[9], since than it is used as a primary screening of HIV.

\section{Chronological development of ELISA with reference} to HIV antibody test: After development and availability in the market of Anti-HIV test, wide range of companies came in this field and worked to improve HIV immunoassay performance. In the early stage of HIV immunoassay, virus particle (lysate) protein was used as an antigen to detect HIV antibody ( $\mathrm{IgG}$ ) and later on called $1^{\text {st }}$ generation HIV immunoassay. For improvement of sensitivity and specificity $2^{\text {nd }}$ generation immunoassay was developed with synthetic peptides or recombinant protein antigens to detect HIV antibody (IgG). These antigens improve the specificity because of elimination of cellular proteins which are contained with virus particle (lysate). Next improvement is $3^{\text {rd }}$ generation immunoassay, this kind of assay detect HIV IgG \&IGgM antibody, hence improved sensitivity. In the $4^{\text {th }}$ generation HIV immunoassay synthetic peptides and recombinant protein antigens detect IgG and IgM for direct format but in indirect format p24 detecting substance is also added. The $4^{\text {th }}$ generation immunoassay maximise the sensitivity for detection of HIV antibody. The specificity of $4^{\text {th }}$ generation immunoassay varies between $97.6 \%$ to $99.8 \%$ [13-15]. Several studies have proven the sensitivity of $4^{\text {th }}$ generation immunoassay in early detection of HIV infection [16-22].

\begin{tabular}{|l|l|l|l|l|}
\hline Generation & $1^{\text {st }}$ Generation & $2^{\text {nd }}$ Generation & $3^{\text {rd }}$ Generation & $4^{\text {th }}$ Generation \\
\hline Antigen used & Viral lysate & $\begin{array}{l}\text { Recombinant protein \& } \\
\text { peptides }\end{array}$ & $\begin{array}{l}\text { Recombinant protein \& } \\
\text { peptides }\end{array}$ & $\begin{array}{l}\text { Recombinant protein } \\
\text { peptides }\end{array}$ \\
\hline ELISA & Indirect & Indirect & Sandwich & Indirect / Sandwich \\
\hline HIV detection & IgG & IgG & IgG \& IgM & IgG \& IgM \& p24 Ag \\
\hline Sensitivity & + & ++ & +++ & ++++ \\
\hline Specificity & + & +++ & +++ & +++ \\
\hline Year & 1985 & 1987 & 1989 & 1997 \\
\hline
\end{tabular}


Source: Constantine, N. T., Saville, D. and Dax E. M. Retroviral testing and quality assurance: Essentials for laboratory diagnostics 2005 .

Chemiluminescence Immunoassay (CLIA):It is a quick, simple, free of hazardous compound like radioactive substances, human error free as performs complete sample processing, ultra-sensitive, clear interpretation of results, wide range of applications, broad linear range, high throughput and quality to detect low abundance of the analyte (biological molecules). Now a day's CLIA is well established as one of the alternative methods of conventional or traditional ELISA for detection and quantitation of samples having antigen and / or antibodies. This technique has also been used as diagnostic tools in medical sciences and also used in various field like environmental monitoring, food safety, pharmaceutical analysis and bacterial identification[23]. Luminol (3aminophthahydrazide), polyphenols and acridine esters are the common Chemiluminescence substrate suitable for horse radish peroxidase. The term chemiluminescence was first coined by Eilhardt Weideman in 1888, Robert Wilson, 1998 used acridan ester as chemiluminescence for horse radish peroxidase[24]. Luminol or acridinium ester is generally used in clinical analysis[24,25]. An alphabetical name of some major players of the CLIA instruments along with kit and reagents are: M/s Abbott Diagnostic, M/s Alere, M/s Arkay, M/s Beckmen Coulter, M/s Bio-Kit, M/s BioMerieux, M/s Bio-Rad, M/s Ortho Clinical Diagnostics, M/s Roche Diagnostics, M/s Siemens Healthcare etc. As per report of Health (The Enterprise of Health), $16^{\text {th }}$ October 2015, CLIA accounted for largest percentage of share (27\%) of the global market in the year 2013 and Indian immunochemistry analysers and reagent market is valued at INR 1510 crore and revenues in form of immunochemistry reagents accounting for INR 1313 crore in 2014.

\section{Conclusion}

Tests to detect antibody to HIV are screening assays which detect all infected individuals and confirmatory (supplementary) assays to differentiate those persons who test false reactive by screening assays from those persons who are truly infected. Accordingly, screening tests possesses a high degree of sensitivity (low false negative rate) whereas confirmatory assays have a high specificity (low false positive rate). $4^{\text {th }}$ generation immunoassay either traditional / conventional ELISA / EIA or CLIA are able to detect an early infection as compared to $3^{\text {rd }}, 2^{\text {nd }}$ and $1^{\text {st }}$ generation HIV detection kit. The $4^{\text {th }}$ generation CLIA has a quality to detect and quantitate separate values for antigen and antibody with better interpretation. Despite of all the progress made so far screening test detecting antigen and / or antibodies, although highly effective in identifying infected persons, will not always detect all individuals who are infected and do not correctly classify persons who are not infected. All tests should be considered as less than perfect and therefore, the results of any one test should not be considered definitive. Even confirmatory tests produce false negative and false positive results[26].

\section{Funding:Nil. Permission for IRB: Yes}

\section{Reference}

1. Yalow R. S. \&Berson S. A. Immunoassay of endogenous plasma insulin in man. Journal of Clinical Investigation. 1960 July;39(7):1157-1175

2. Graham A. Bonwick\& Christopher J. Smith. Immunoassays: their history, development and current place in food science and technology. International Journal of food Science and Technology.2004 Oct; 39(8):817-827. doi: 10.1111/j.1365-2621.2004.00855.

3. www.elisa-antibody.com/ELISA-Introduction, ELISA enclyclopedia.

4. Engvali E and Perlmann P. Enzyme-linked immunosorbent assay (ELISA). Quantitative assay of immunoglobulin G. Immunochemistry. 1971Sep;8(9):871-4.

5. Rudolf M. Lequin. Enzyme Immunoassay (EIA) / Enzyme-Linked Immunosorbent Assay (ELISA).Clin Chem. 2005 Dec;51(12):2415-18.Doi 10.1373/clinchem2005.051532.

6. Van Weemen B.K. and Schuurs A.H.W.M. Immunoassay using Antigen-Enzyme Conjugates. FEBS Letters.1971 July;15(3):232-236.

7. Stephanie D Gan and Kruti R Patel. Enzyme Immunoassay and Enzyme-Linked Immunosorbent Assay.Journel of Investigate Dermatology. 2013. 133,e12.doi:10.1038/jid.2013-287. 
8. Wolters G, Kuijpers L.P.C., Kacaki J, Schuurs A.H.W.M. Enzyme -immunoassay for HBsAg. 1976; Lancet II:690.

9. WHO 2004 Rapid HIV tests: Guidelines for use in HIV testing and counselling service in resourceconstrained settings, Geneva.

10. CDC Public Health Service inter-agency guidelines for screening donors of blood, plasma, organs, tissues, and semen for evidence of hepatitis B and hepatitis C. MMWR 1991;40(No. RR-4):1--17.

11. Guidelines for Laboratory Testing and Result Reporting of Antibody to Hepatitis C Virus*. February 7, MMWR 2003/52(RR03):1-16.

12. Raphael Wong and Harley Tse. Lateral Flow immunoassay. Humana Press. New York. 2009 edition. $1-224$.

13. Salmona M, Delarue S, Delaugeree C, Simon F, Maylin S. Clinical evaluation of BioPlex® 2200 HIV $\mathrm{Ag}-\mathrm{Ab}$ : an automated screening method providing discrete detection of HIV-1 p24 antigen, HIV-1 antibody and HIV 2 antibody. Journal Clinical Microbiology.2014 Jan;52(1):103-7.doi: 10.1128/JCM.02460-13.

14. Brust S, Duttmann H, Feldner J, Gurtler I, Thorstensson R, Simon F. Shortening of the diagnostic window with a new combined HIV p24 antigen and anti-HIV-1/2 O screening test. Journal Virology Methods. 2000 Nov; 90(2):153-165.

15. Alonso R, Roa P.L. Suarez M, Bouza E. New automated chemiluminescence immunoassay for simultaneous but separate detection of human immunodeficiency virus antigens and antibodies. Journal of Clinical Microbiology.2014; 52(5):1467-70.

16. Weber B, Berger A, Rabenau H, Doerr HW. Evaluation of a new combined antigen and antibody human immunodeficiency virus screening assay, VIDAS HIV DEO Ultra. Journal of Clinical Microbiology.2002 April; 40(4):1420-26.

17. Weber B, Orazi B, Raineri A, Thorstensson R, Burgisser P, Muhlbacher A, Areal C, Eiras A, Villaescusa R, Camacho R, Diogo I, Roth HJ, Zahn I, Bartel J, Bossi V, Piro F, Atamasirikul K, Permpikul P, Webber I, Singh S.Multicenter evaluation of a new $4^{\text {th }}$ generation HIV screening assay Elecsys HIV conbi. Clinical Lab.2006;52(9-10):463-73.

18. Muhlbacher A, Schennach H, van Helden J, Hebell T, Pantaleo G, Burgisser P, Cellerai C, Permpikul P, Rodriguez M I, Eiras A, Alborino F, Cunningham P, Axelsson S, Wetlizky O, Kaiser C, Moller P, de Sousa G. Performance evaluation of a new fourth generation HIV combination antigen-antibody assay. Medical Microbiology Immunology.2013 Feb; 202(1):77-86.

19. Pumarola T, Freeman J, Saxton E, Dillon P, Bal T, van Helden J. Performance evaluation of the ADVIA Centaur ${ }^{\circledR}$ HIV Ag/Ab Combo assay. Journal Virology Methods.2010 Dec;170 (1-2):16-20.doi: 10.1016/j.jviromet.2010.

20. Kwon JA, Yoon SY, Lee CK, Lim CS, Lee KN, Sung HJ, Brennan CA, Devare SG. Performance evaluation of three automated human immunodeficiency virus antigen-antibody combination immunoassay. Journal Virology Methods. 2006 Apr; 133(1):20-26.

21. Malm K, von Sydow M, AnderssonS.Performance of three automated fourth generation combined HIV antigen/antibody assays in large-scale screening of blood donors and clinical samples. Transfusion Medicine. 2009; 19(2):78-88.

22. Roberto A, Paula LR, Marisol S, Emilio B. New automated chemiluminescence immunoassay for simultaneous but separate detection of human immunodeficiency virus antigens and antibodies. Journal of Clinical Microbiology.2014; 52:1467-70.

23. Wang Chen, WU Jie, Zong Chen, XU Jie,JU Huang-Xian. Chemiluminescent immunoassay and its applications. Chinese Journal of Analytical Chemistry.2012 Jan; 40(1),3-10.

24. Araujo-Filho J.L.S., Melo-Junior M.R. and Carvalho Jr L. B. Potential applications of the chemiluminescent methods in tumoral diseases investigation; International Journal of Pharma and Bio Sciences.2011; 2(2)392-400.

25. Lin $\mathrm{J}$, and $\mathrm{Ju} \mathrm{H}$. Electrochemical and chemiluminescent immunosensors for tumor markers.BiosensBioelectron.2005 Feb 15; 20(8):146170 . 
26. Constantine, N. T., Saville, D. and Dax E. M. laboratory diagnostics. 2005; 1-771.

Retroviral testing and quality assurance: Essentials for

\section{How to cite this article?}

Sharma R K, Sharma S K, Brij Bhushan, Sharma D, Arun Kumar,Chhabra R, Soni G R, Singh S. Evolution of immunoassay with reference to HIV: brief review. Int $J$ Med Res Rev 2015;3(10):1234-1238. doi: 10.17511/ijmrr.2015.i10.224. 